ROSIANE MATTAR

Márcia Maria Auxiliadora de Aquino²

Maria Rita de Souza MesQUita

\title{
A prática da episiotomia no Brasil
}

\author{
The practice of episiotomy in Brazil
}

Dois temas são muito importantes para as atividades exercidas pelos profissionais de saúde: a medicina baseada em evidências e a ativação de processos de mudança. A transformação de atitudes e condutas antigas mantidas como verdades absolutas ocorrerá somente se estes dois processos caminharem juntos.

$\mathrm{Na}$ atualidade, dentre os vários temas discutidos em Medicina, destacamos um dos procedimentos mais comuns em Obstetrícia: a episiotomia na assistência ao parto normal.

A primeira menção à episiotomia foi feita por Ould, em 1741, como método de prevenção de lacerações severas a ser utilizado excepcionalmente. No entanto, esta intervenção passou a ser recomendada sistematicamente por dois eminentes ginecologistas, De Lee e Pomeroy, na primeira metade do século passado, período que coincidiu com o início da prática da hospitalização para a assistência ao parto ${ }^{1}$.

De Lee (1915) indicou o uso da episiotomia rotineira, preferindo a incisão médiolateral, enquanto Pomeroy (1918) expressou sua preferência pela episiotomia mediana ou periotomia, principalmente nas primigestas, para evitar roturas perineais extensas ${ }^{1}$.

Neste período, a episiotomia era utilizada de modo profilático, tendo como objetivos primordiais a prevenção de traumas perineais, redução da morbimortalidade infantil e diminuição da ocorrência de retocele e cistocele, além do relaxamento da musculatura pélvica².

Este modelo vem sendo adotado e ensinado pela Obstetrícia brasileira como conduta bem estabelecida e universalmente aceita, com base em justificativas que incluem a prevenção do trauma perineal severo e dos danos do assoalho pélvico, visando evitar prolapsos genitais e incontinência urinária ${ }^{3}$ futuros. Esta profilaxia, segundo os cirurgiões, justificaria a dor acarretada pela incisão e eventuais complicações locais.

Entretanto, nas últimas décadas, alguns estudos com o objetivo de reduzir as intervenções desnecessárias e a morbiletalidade materno-fetal têm avaliado a prática rotineira da episiotomia no período expulsivo do parto. Uma revisão sistemática publicada pela biblioteca Cochrane (2006) ${ }^{4}$ concluiu que a episiotomia seletiva, se comparada à rotineira em todos os partos vaginais, associou-se a menor risco de trauma de períneo posterior, a menor necessidade de sutura e a menos complicações na cicatrização.

As evidências demonstram que o uso rotineiro da episiotomia não reduz o risco de trauma perineal severo (lacerações de $3^{\circ}$ e $4^{\circ}$ graus), não previne lesões no pólo cefálico fetal 
e nem melhora os escores de Apgar. Além disto, promove maior perda sangüínea e não reduz o risco de incontinência urinária de esforço, dispareunia e dor perineal após o parto ${ }^{4}$.

A única real evidência a favor do uso sistemático da episiotomia foi uma diminuição do risco de traumatismo perineal anterior. Cumpre lembrar que este tipo de laceração normalmente cursa com menos sangramento, não necessita de sutura e é menos dolorosa que os traumas de períneo posterior.

Os autores da revisão concluem que a episiotomia seletiva traz maiores benefícios que o uso rotineiro, sendo indicada em situações de sofrimento fetal, feto em apresentação pélvica, progressão insuficiente do parto e ameaça de laceração perineal de terceiro grau .

Apesar dos questionamentos sobre a validade da episiotomia rotineira na prática obstétrica, a prevalência deste procedimento é elevada e bastante variada conforme a região do mundo estudada ${ }^{5}$. Estima-se que seja empregada em 62,5\% do total de partos nos Estados Unidos e em cerca de 30\% na Europa, enquanto que na América Latina, ainda vem sendo utilizada como intervenção de rotina em toda primípara e em parturientes com episiotomia prévias.

Não está totalmente estabelecida qual a freqüência ideal do uso deste procedimento como uma política de saúde. O Ministério da Saúde do Brasil, apesar de recomendar o seu uso seletivo, não determina a taxa ideal a ser atingida. Estima-se, por alguns autores, que uma freqüência ótima deveria situar-se entre 10 a $30 \%$ do total de partos vaginais ${ }^{6}$.

É necessário ressaltar que a episiotomia é, no entanto, um dos únicos procedimentos realizados sem qualquer consentimento prévio da paciente, prática esta de fundamental importância.

Outro fator que ainda deve ser considerado é o alto custo monetário quando se adota este procedimento como rotina, levando-se em conta o gasto com material utilizado em sua realização e reparo, além do maior tempo de internação hospitalar, fator este de capital importância para países pobres como o nosso.

Embora já se tenha comprovado que a prática rotineira da episiotomia não constitui bom exercício da Obstetrícia, a maioria dos obstetras, mesmo os responsáveis pelo ensino médico, não consegue abandoná-la, pois ela lhes foi ensinada nos bancos universitários e eles se acostumaram a ela.

É difícil mudar atitudes que fazem parte de nossas vidas a ponto de se tornarem hábitos, mesmo quando se trata de condutas inadequadas. Entretanto, a partir das evidências científicas que comprovam a efetividade da episiotomia seletiva, a mudança de conduta se faz necessária, porque, certamente, resultará em assistência mais humanizada e de melhor qualidade às parturientes.

Por isto, acreditamos que este editorial possa representar mais um fator ativador da discussão da prática da episiotomia seletiva. É necessário que os profissionais se transformem. Sem transformação não há evolução.

\section{Referências}

1. Neme B. Obstetrícia básica. 2a ed. São Paulo: Sarvier; 2000. p. 190-213.

2. Graham ID. Episiotomy: challenging obstetric interventions. London: Blackwell Science; 1997. p. 33-41.

3. Ecker JL, Tan WM, Bansal RK, Bishop JT, Kilpatrick SJ. Is there a benefit to episiotomy at operative vaginal delivery? Observations over ten years in a stable population. Am J Obstet Gynecol. 1997;176(2):411-4.

4. Carroli G, Belizan J. Episiotomy for vaginal birth (Cochrane Review). In: The Cochrane Library, Issue 1, 2006. Oxford: Update Software.

5. Organização Mundial de Saúde. Saúde Materna e Neonatal. Unidade de Maternidade Segura, Saúde Reprodutiva e da Família. Assistência ao parto normal: um guia prático. Genebra; 2000.

6. Ministério da Saúde. Secretaria de Políticas de Saúde. Área Técnica de Saúde da Mulher. Parto, aborto e puerpério: assistências humanizadas à mulher. Brasília; 2001. 